vorstellungen, die von unseren Referenten wieder hervorragend präsentiert wurden. Molekulare Allergiediagnostik und neue Therapieoptionen mit Biologics wurden diesmal besonders diskutiert.

? Wie viele Teilnehmer waren es 2016 und wie war die Verteilung?

Darsow/Raap: Wir hatten insgesamt 80 Teilnehmer, mit einer Verteilung der Teilnehmer auf die jeweiligen Fächer von ungefähr 30\% Dermatologen, 20\% Internisten/Pneumologen, $20 \%$ HNO-Ärzte sowie Pädiater, Allgemein- und Labormedizinern.

? Wird es 2017 wieder eine Fortsetzung in Hannover geben? Sind hier Änderungen oder Neuerungen in Planung?

Darsow/Raap: Wir freuen uns schon jetzt darauf, die nächste Allergologie-KompaktVeranstaltung zu planen, die 2017 in Hannover stattfinden wird. Als bewährtes Organisationsteam werden wir wieder die

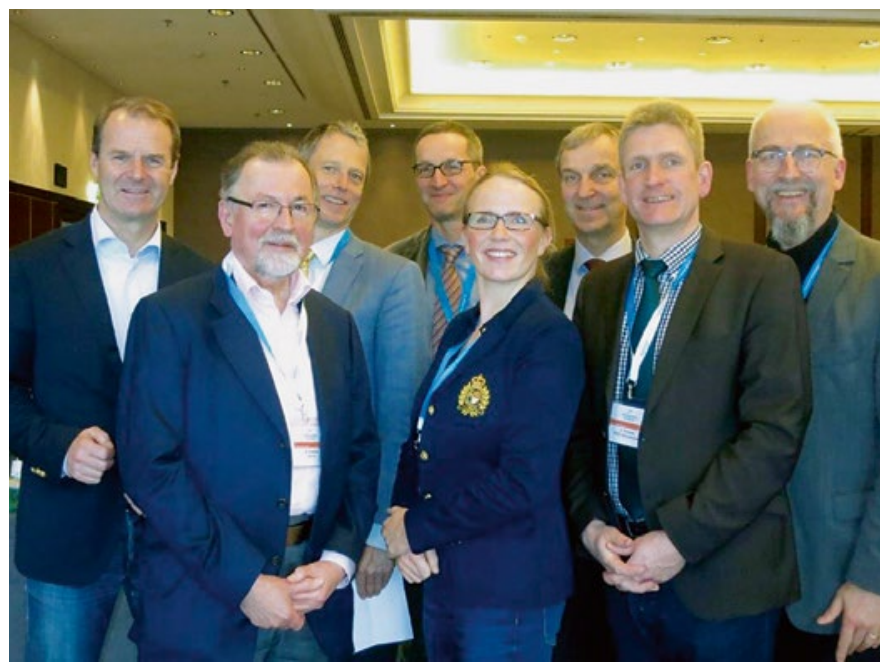

ein oder andere Änderung vornehmen, damit Allergologie Kompakt jedes Jahr auf dem aktuellsten Stand bleibt. Ein Highlight wird das Buch zu Allergologie Kompakt sein, das demnächst im Dustri Verlag er- scheint. Wir bedanken uns für das Interview.

! Vielen Dank für das Gespräch!

Das Interview führte Marion Weber.

\section{Allergologie im Kloster}

Zum 12. Mal findet in diesem Jahr das interdisziplinäre Symposium "Allergologie im Kloster" statt - am 20. und 21. Mai in den historischen Gemäuern des Kloster Eberbach in Eltville, Rheingau.

Tagungsleiter Prof. Dr. Ludger Klimek lädt alle Interessierten herzlich ein: „Porta patet, cor magis - die Tür steht offen, mehr noch das Herz! Seit einigen Jahren dürfen wir Allergologen uns jeweils im Wonnemonat Mai diesem Wahlspruch folgend im Rheingau zusammenfinden, um aktuelle Forschungsergebnisse auszutauschen und Weiterbildungsreferate auf hohem Niveau zu verschiedenen Themen zu hören.

Hier die Hauptvorträge von Allergologie im Kloster 2016:

_ Differenzierte Therapie der Sinusitis. L. Klimek

_ Nutzen und Grenzen der Allergenkennzeichnung bei

Lebensmitteln. M. Auge

_ Die Immuntherapie der Zukunft: Immunregulatorische Epitope, Peptide und mehr. $n$. $n$.

- The new frontier for Upper Airway Inflammatory treatment. J. Mullol

_ Schweres Asthma: Definition, Diagnostik und Therapie. M. Lommatzsch

- Was passiert bei der allergischen Entzündung in den Atemwegen? C. Schmidt-Weber

_ Wie sollte die allergikerfreundliche Stadt aussehen? J. Buters

- Riechen und Allergien. T. Hummel

- Welche Allergene finden sich eigentlich in deutschen Haushalten? Mehr als Hausstaubmilben. H. Müsken

Darüber hinaus wird es wieder einige praktische Workshops geben, wie zum Beispiel einen Allergiediagnostik-, einen Anaphylaxie- und einen Milben-Workshop. Speziell für Medi- zinische Fachangestellte wird der „Intensivworkshop Notfallmanagement" angeboten.

\section{Anmeldung und Information}

Katja Reichardt

Zentrum für Rhinologie und Allergologie

An den Quellen 10

65183 Wiesbaden

Tel.: (06 11) 308608290

Fax: (06 11) 308608295

E-Mail: info@allergologie-im-kloster.org

Internet: www.allergologie-im-kloster.org

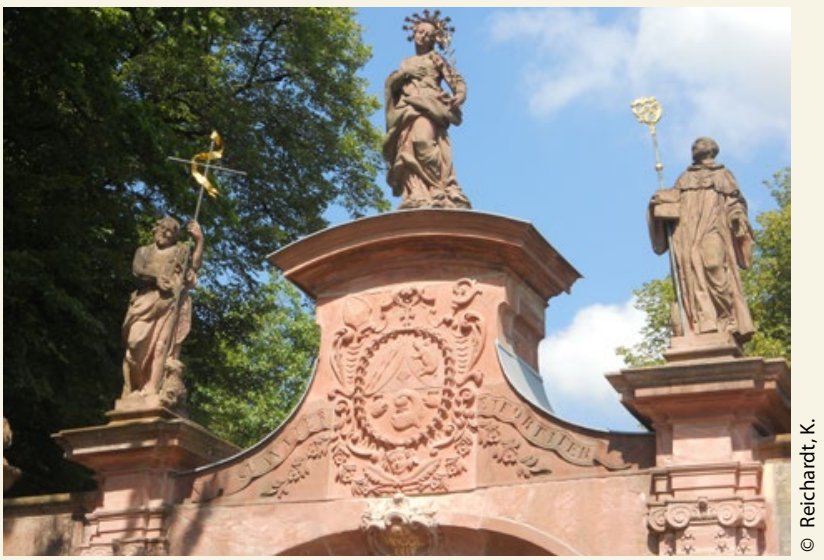

